Research Article

\title{
Interaction of Cyclic Loading (Low-Cyclic Fatigue) with Stress Corrosion Cracking (SCC) Growth Rate
}

\author{
Rehmat Bashir, ${ }^{1,2}$ He Xue $\mathbb{D}^{1},{ }^{1}$ Rui Guo $\mathbb{D}^{1},{ }^{1}$ Yueqi Bi $\mathbb{D},{ }^{1}$ and Muhammad Usman ${ }^{2}$ \\ ${ }^{1}$ School of Mechanical Engineering, Xi'an University of Science and Technology, Xi'an 710054, China \\ ${ }^{2}$ Department of Mechanical Engineering, University of Engineering and Technology (Main Campus), Lahore 54890, Pakistan
}

Correspondence should be addressed to He Xue; xue_he@hotmail.com

Received 10 December 2019; Accepted 19 March 2020; Published 13 April 2020

Academic Editor: Hongtao Zhu

Copyright (C) 2020 Rehmat Bashir et al. This is an open access article distributed under the Creative Commons Attribution License, which permits unrestricted use, distribution, and reproduction in any medium, provided the original work is properly cited.

\begin{abstract}
The structural integrity analysis of nuclear power plants (NPPs) is an essential procedure since the age of NPPs is increasing constantly while the number of new NPPs is still limited. Low-cyclic fatigue (LCF) and stress corrosion cracking (SSC) are the two main causes of failure in light-water reactors (LWRs). In the last few decades, many types of research studies have been conducted on these two phenomena separately, but the joint effect of these two mechanisms on the same crack has not been discussed yet though these two loads exist simultaneously in the LWRs. SCC is mainly a combination of the loading, the corrosive medium, and the susceptibility of materials while the LCF depends upon the elements such as compression, moisture, contact, and weld. As it is an attempt to combine SCC and LCF, this research focuses on the joint effect of SCC and LCF loading on crack propagation. The simulations are carried out using extended finite element method (XFEM) separately, for the SCC and LCF, on an identical crack. In the case of SCC, $\mathrm{d} a / \mathrm{d} t(\mathrm{~mm} / \mathrm{sec})$ is converted into $\mathrm{d} a / \mathrm{d} N_{S c c}(\mathrm{~mm} /$ cycle), and results are combined at the end. It has been observed that the separately calculated results for SCC $\left(\mathrm{d} a / \mathrm{d} N_{\mathrm{Scc}}\right)$ and LCF $\left(\mathrm{d} a / \mathrm{d} N_{m}\right)$ of crack growth rate are different from those of joint/overall effect, $\left[\mathrm{d} a / \mathrm{dN}_{o}\right]_{m}$. By applying different SCC loads, the overall crack growth is measured as SCC load becomes the main cause of failure in LWRs in some cases particularly in the presence of residual stresses.
\end{abstract}

\section{Introduction}

Mechanical fatigue and SCC are two important types of failure in the LWRs $[1,2]$. The word fatigue was firstly originated from the Latin word Fatigare which means "to tire" and commonly associated with mental and physical weariness in the people. After the industrial revolution in the $19^{\text {th }}$ century, it has become accepted engineering terminology for damage and failure of materials under cyclic loads $[3,4]$. Resistance to the fatigue by the material can be classified into following regimes: low-cycle fatigue (or short life) or limited resistance ( $10^{4}$ and $10^{5}$ cycles), high-cycle fatigue ( $10^{6}$ to $10^{7} \mathrm{cycles}$ ), and gigacycle fatigue (more than $10^{7}$ cycles) [5]. The fatigue caused by the small elastic strains under a high number of load cycles before failure occurs is called high-cycle fatigue. The stress in case of high-cycle fatigue comes from a combination of mean and alternating stresses. The mean stress is caused by residual stress, the assembly load, or strongly nonuniform loading [6]. However, LCF is fatigue in which the plastic deformation is considered in each cycle. LCF has two characteristics: plastic deformation in each cycle and low-cycle phenomena $[7,8]$. The failure due to the crack propagation in the case of LCF is more prominent as compared to that in case of high-cyclic fatigue (see Figure 1). Most of the time, LCF is the cause of failures, so the LCF is considered in this research.

Stress corrosion cracking (SSC) is another major factor in the life of NPP materials. This is the most important field in the safety of NPPs. Most authors [9] define that SSC is a conjoint contribution of stresses, environment, and chemical action to the failure of metals. The necessary characteristic conditions for SCC are tensile stresses, a specific environment, an environmental susceptibility of the material (metallurgical aspect), and time $[10,11]$. SSC is an 


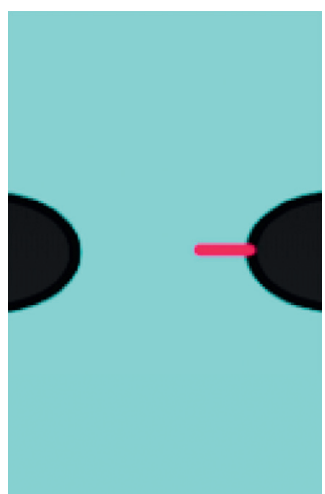

(a)

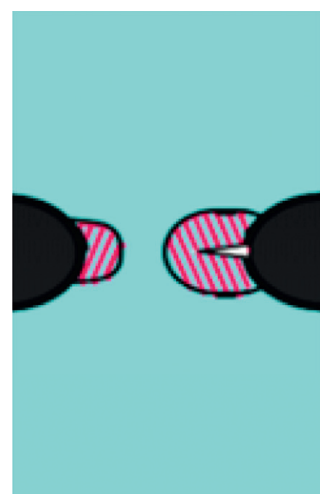

(b)
Figure 1: (a) High-cyclic fatigue and (b) low-cyclic fatigue.

electrochemical anodic process involving environmentally assisted conditions, stresses, and material properties at the crack tip and orientation of piping in LWRs [12].

In order to predict the structural integrity, the life of the service, and safety of the low boiling LWRs, quantitative prediction of crack growth rate is an essential feature [13]. A wide range of variables can influence the environmental fatigue and the SCC crack growth rate for metallic materials [14].

Different models have been presented to measure the fatigue crack propagation rate and SCC crack growth rate. Predan et al. [15] studied the effect of residual stresses on the crack propagation. Fatigue crack propagation experiments were conducted on notched bending specimen and it was observed that residual stresses induced the variations in crack propagation rate. Paris and Erdogan [16] proposed the following equation for crack propagation:

$$
\frac{\mathrm{d} a}{\mathrm{~d} N_{m}}=C(\Delta K)^{m} .
$$

where $C$ and $m$ are material constants which depend on stress ratio, $R$.

Elber [17] presented the concept of crack closure which correlates the crack growth to different R. In the literature, partial crack closure models are also available [18]. There are more different models: a two-parameter method using stress intensity range, $\Delta K$, and the maximum stress intensity factors, $K_{\max }$, in a cycle to describe the fatigue crack propagation and some other models based on temperature and the residual stresses [19-22]. Similarly, Xue et al. put in a lot in the field of the SCC crack growth rate [23]. In none of the abovementioned models, the effect of SCC on the fatigue crack propagation rate or the effect of cyclic load (fatigue) on the SCC crack growth rate was considered.

Terms should not be mixed with corrosion fatigue (CF). There is a difference between CF and the SCC. CF was introduced in the 1930s when the effect of the corrosive environment on the fatigue loading for metals was studied [24]. CF is the joint action of fatigue and a corrosive environment. It involves the alternating load. However, in the case of SCC, there is a constant loading along with the material properties and environment to affect the mechanism. In this research, it is the SCC loading and the fatigue loading which is being considered.

Recent studies have shown that SCC and fatigue, i.e., cyclic loading, both are present at a time on many structures of metallic materials $[25,26]$, and the SCC environment (load, environmental conditions, and material susceptibility) has many influences on the fatigue crack growth rate, and vice versa. As an example, strain-induced corrosion cracking (SICC) is used for the situation where cracking takes place under increasing load which may not be increasing necessarily monotonically, but also some cyclic variations are present at start-up and shut down situations of the plants [27]; also during smooth operation, both the loadings, i.e., fatigue (cyclic) and stress corrosion, are present.

In this study, the cyclic load is introduced in the SCC loading while keeping the environment and the material constant for SCC and the crack growth rates for the SCC $\left(\mathrm{d} a / \mathrm{d}_{\mathrm{Scc}}\right)$ and cyclic $(\mathrm{LCF})\left(\mathrm{d} a / \mathrm{d} N_{m}\right)$ have been calculated to demonstrate the effect on overall crack growth rate $\left[\left(\mathrm{d} a / \mathrm{d} N_{o}\right)\right]_{m}$, which takes into account these two effects on the same crack simultaneously.

\section{Materials and Methods}

Austenitic stainless steel is an important material used extensively in an aggressive environment like LWRs [28]. Low carbon stainless steel-304 is used in this research, which is an important type of stainless steel that has been used in many applications [29, 30]. Chemical and mechanical properties are shown in Tables 1 and 2. For plastic properties, the tensile true stress-strain curve is shown in Figure 2(a). Since real structures provide results closer to the actual values; therefore, a simple plate of $100 \mathrm{~mm} \times 50 \mathrm{~mm}$, having an extended finite element method (XFEM) crack with $15 \mathrm{~mm}$ length, is used as shown in Figure 2(b) along with the boundary conditions and load. The simulations are divided into two parts. In the first step, the simulation for static loading is performed using XFEM, and then, in the second step, direct cyclic load (using low-cycle fatigue) is applied on an identical crack and results in both the cases are superpositioned to get the combined effect on the same crack.

In the case of simulation of the static loading, the uniformly distributed static general loads of 200, 240, and $270 \mathrm{MPa}$ are applied separately on the top of the plate. While the lower side is fixed, the right side can elongate in the vertical direction only. The crack growth rate in case of the SCC, $\left(\mathrm{d} a / \mathrm{d}_{\mathrm{Scc}}\right)$, is measured. For direct cyclic load, $200 \mathrm{MPa}$ is applied at a stress ratio $=-1$, on the identical crack, and crack growth rate, $\left(\mathrm{d} a / \mathrm{dN}_{m}\right)$, in this case, is also measured. All the simulations are performed in the ABAQUS 6.14 software following the instructions provided in the manual [31].

\section{Simulations}

3.1. XFEM. XFEM is now widely used in the crack simulations. In the case of XFEM, no remeshing is required. In XFEM, during the analysis, the enrichment function consists of the near-tip asymptotic functions that capture the 
TABLE 1: Chemical composition of the used stainless steel (wt\%).

\begin{tabular}{ccccccccc}
\hline Steel & $\mathrm{C}$ & $\mathrm{Si}$ & $\mathrm{Mn}$ & $\mathrm{P}$ & $\mathrm{S}$ & $\mathrm{Cr}$ & $\mathrm{N}$ & $\mathrm{Ni}$ \\
\hline 304 & 0.08 & 0.75 & 2.00 & 0.045 & 0.03 & $18-20$ & .10 & $8-10$ \\
\hline
\end{tabular}

TABLE 2: Elastic properties of the SS-304 used.

\begin{tabular}{lcccc}
\hline Material & Elastic modulus $(\mathrm{GPa})$ & Maximum principle stress $(\mathrm{MPa})$ & Poisson's ratio $(\mathrm{v})$ & Elongation $(\%)$ \\
\hline $\begin{array}{l}\text { Stainless steel- } \\
304\end{array}$ & 210 & 550 & 0.32 & 40 \\
\hline
\end{tabular}

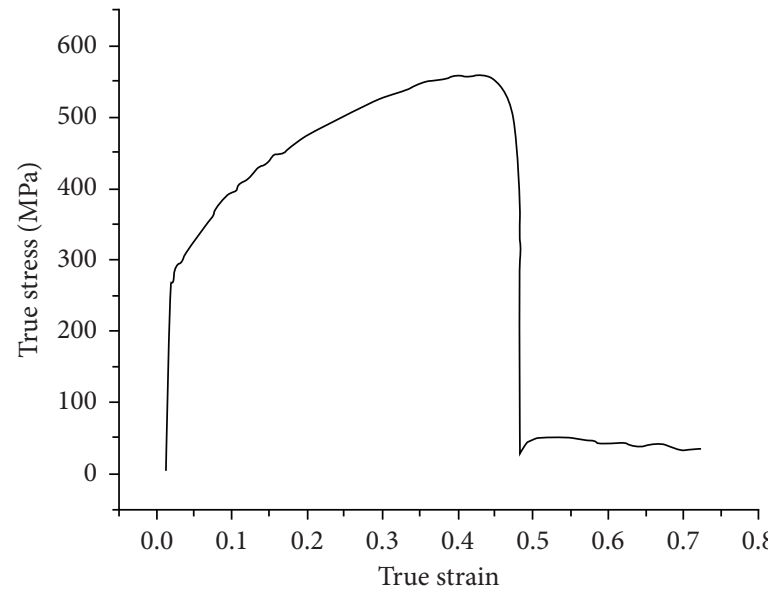

- SS-304 in $320^{\circ} \mathrm{C}$

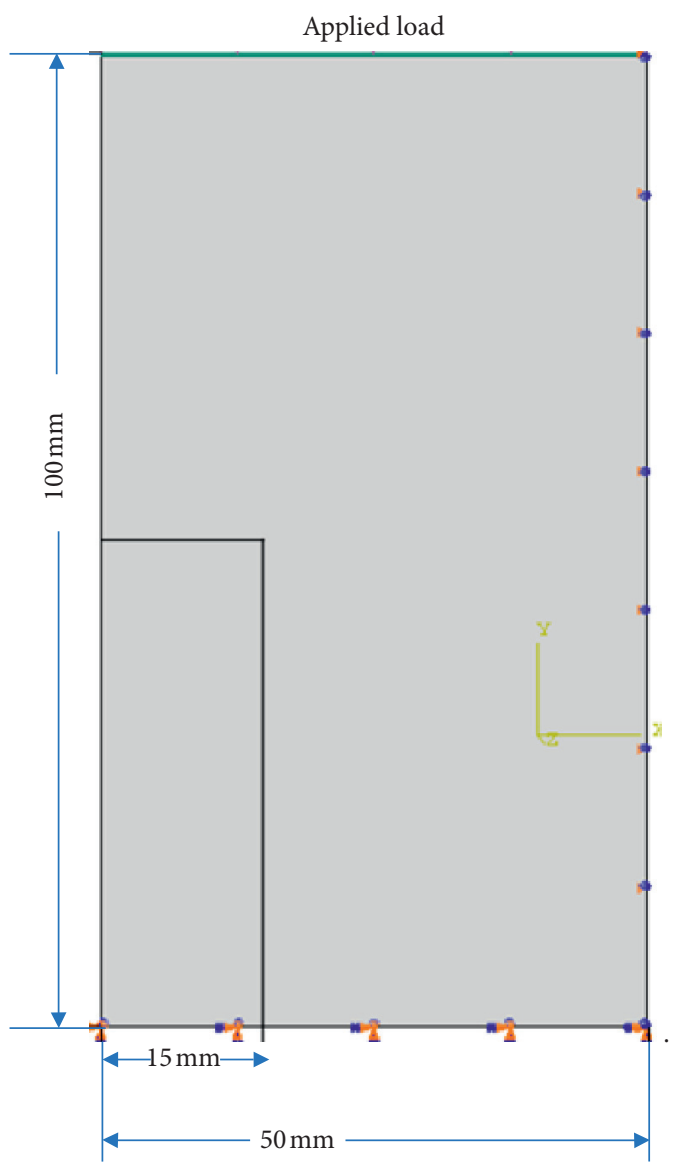

(b)

Figure 2: (a) The true tensile strain curve at high temperature. (b) 2D element used along with loading and boundary conditions.

singularity around the crack tip and a discontinuous function that represents the jumps in the displacement across crack surfaces. The approximation for a displacement vector surface with the partition of unity enrichment [32] is given by

$$
N=\sum_{i=1}^{n} N_{i}(X)\left[u_{i}+H(X) a_{i}+\sum_{i=1}^{4} F_{a}(X) b_{i}^{a}\right]
$$

where $N_{i}(X)$ is called usual nodal shape function; $u_{i}$ is the usual nodal displacement vector associated with the continuous part of the finite element solution; $H(X)$ is the discontinuous jump functions across the crack surface, also named as Heaviside function, which is associated with the product of the nodal enriched degree of freedom vector, $a_{i}$; and the third term is the nodal enriched degree of freedom vector, $b_{i}^{a}$, and the associated elastic asymptotic crack tip function, $F_{a}(X)$. The first term on the right-hand side is applicable to all the nodes in the model; the second term is applicable to all the nodes whose shape function support is cut by the crack interior, and the third term is only for those nodes whose shape function support is cut by crack tip [33, 34].

3.2. SCC. The SCC is done in ABAQUS/standard model crack subjected to critical static general loading available in the software. F-A model is established by Ford and Anderson of General Corporation [35] which is widely used 
in high-temperature water environments based on the theory of slip dissolving film rupture. The specific expression of the model is shown as follows:

$$
\frac{\mathrm{d} a}{\mathrm{~d} t}=\kappa_{a} \cdot\left(\dot{\varepsilon}_{\mathrm{ct}}\right)^{m}
$$

where $m$ is the exponent of the current decay curve which is related to the corrosion potential, solution conductivity, and chromium depletion. $\dot{\varepsilon}_{\mathrm{ct}}$ is the strain rate at the crack tip; $\kappa_{a}$ is the oxidation rate constant, which is determined by the environment and material in the vicinity of the crack tip and is given by

$$
\kappa_{a}=\frac{M}{\rho \cdot F \cdot z} \cdot \frac{i_{0}}{1-m} \cdot\left(\frac{t_{0}}{\varepsilon_{f}}\right)^{m},
$$

where $M$ is the metal molecular weight; $\rho$ is the metal density; $F$ is Faraday's constant; $z$ is the change in charge during the oxidation process; $i_{0}$ is the oxidation current density of the bare surface; $t_{0}$ is the time before the onset of the current decay; and $\dot{\varepsilon}_{f}$ is the oxide film degradation strain.

Considering that it is difficult to obtain the strain rate at the crack tip in the F-A model, a crack tip strain rate model based on the theory of crack tip strain gradient was deduced by Professor Shoji of Japan Northeast University and in equation (3). FRI model establishes the relationship between the crack tip strain rate and macromechanical parameters [36] which has been adopted by many laboratories around the world. Meanwhile, engineering applications have also been achieved to some extent, but the crack tip characteristic distance $r_{0}$ in the model has not been given a clear definition.

$$
\dot{\varepsilon}_{c t}=\beta \frac{\sigma_{y s}}{E} \frac{N}{N-1}\left(\frac{\dot{a}}{K}\right)\left[\ln \left(\frac{R_{P}}{r_{0}}\right)\right]^{1 /(N-1)} .
$$

To obtain the strain rate at the crack tip, Xue et al. proposed an alternative algorithm of the strain rate at the crack tip that is the plastic strain at $r_{0}$ in front of the crack tip and is used to replace the strain at the crack tip, as shown in equation (6), where $r_{0}$ is a distance from the front of the crack tip [37]:

$$
\varepsilon_{\mathrm{ct}}=\varepsilon_{p} \mid r=r_{0} .
$$

The variation of the distance $r$ will cause an increase of crack tip strain when the crack is growing:

$$
\varepsilon_{\mathrm{ct}}=\dot{\varepsilon}_{p}=\frac{\mathrm{d} \varepsilon_{p}}{\mathrm{~d} a} \cdot \frac{\mathrm{d} a}{\mathrm{~d} t},
$$

where $\mathrm{d} \varepsilon_{p} / \mathrm{d} a$ is the strain rate at a characteristic distance $r_{0}$ in front of the growing crack tip. Substituting equation (7) into (3), the SCC growth rate at the crack tip in a hightemperature water environment can be expressed as follows:

$$
\frac{\mathrm{d} a}{\mathrm{~d} t}=\kappa_{a}^{\prime} \cdot\left(\frac{\mathrm{d} \varepsilon_{p}}{\mathrm{~d} a}\right)^{m /(1-m)},
$$

where $\kappa_{a}^{\prime}=\left(\kappa_{a}\right)^{1 /(1-m)}$, for a stable propagation crack tip, equation (3) can be expressed as equation (8), and the calculation method of the tensile plastic strain rate at the crack tip is shown in Figure 3 where

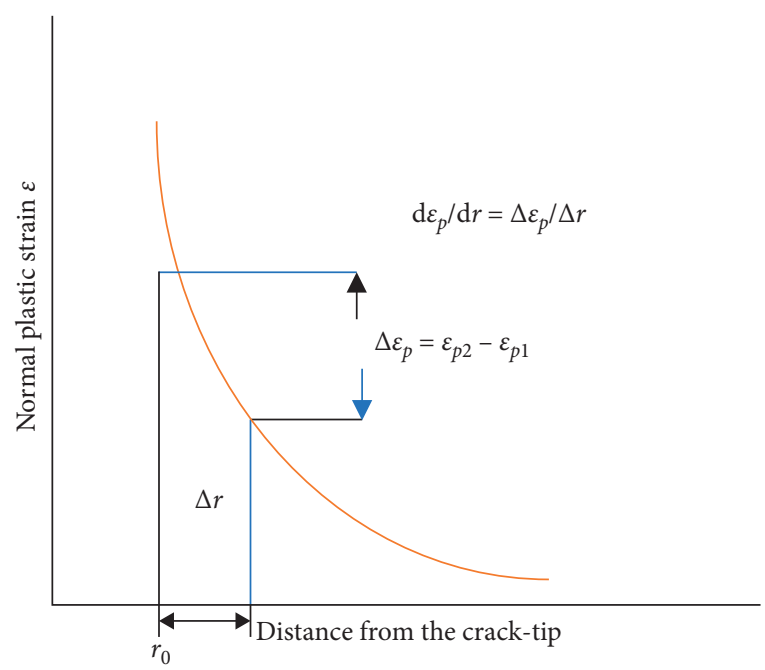

Figure 3: Process of calculating strain gradient with respect to crack distance.

$$
\frac{\mathrm{d} \varepsilon_{p}}{\mathrm{~d} a}=-\frac{\mathrm{d} \varepsilon_{p}}{\mathrm{~d} r} .
$$

Substitute equation (9) into (8) to obtain the expression of the SCC crack growth rate, as shown in the following equation:

$$
\frac{\mathrm{d} a}{\mathrm{~d} t}=\kappa_{a}^{\prime} \cdot\left(\frac{\mathrm{d} \varepsilon_{p}}{\mathrm{~d} r}\right)^{m /(1-m)}
$$

3.3. LCF. The low-cyclic fatigue criterion is done by using the option available in ABAQUS/standard model crack subjected to critical cyclic loading. The fatigue crack propagation is characterized by using Paris law which relates the crack growth rate, $\left(\mathrm{d} a / \mathrm{d} N_{m}\right)$, to the range of energy release rate at the crack tip. The fatigue crack initiation is governed by the following equation:

$$
f=\frac{N}{c_{1} \Delta G^{c_{2}}} \geq 1
$$

where $N$ is the number of cycles and $c_{1}$ and $c_{2}$ are the material constants, and their values are taken to be $1 \times 10^{-4}$ and -1 , respectively. The fatigue crack propagates according to the Paris regime (see Figure 4). The enriched element will only let the crack propagate when the $G_{\max }>G_{\text {thresh }}$. Here, the Paris regime is characterized by $\Delta G$ where $G_{\max }$ and $G_{\min }$ are the potential energies release rate when the component is reached up to maximum, $P_{\max }$, and minimum, $P_{\text {min }}$, loading, respectively. The Paris regime is confined between $G_{\text {thresh }}$ and $G_{p l}$, and below $G_{\text {thresh }}$, there is no crack initiation, and above $G_{p l}$, the crack grows abruptly and these two values should be specified in the model. $G_{c}$ is the fracture energy of the material which is used as $G_{\text {equivC }}$ calculated based on the user-specified behavior of the crack.

Once the crack starts propagating, the fatigue crack growth rate, $\left(\mathrm{d} a / \mathrm{d} N_{m}\right)$, can be measured by using energy 


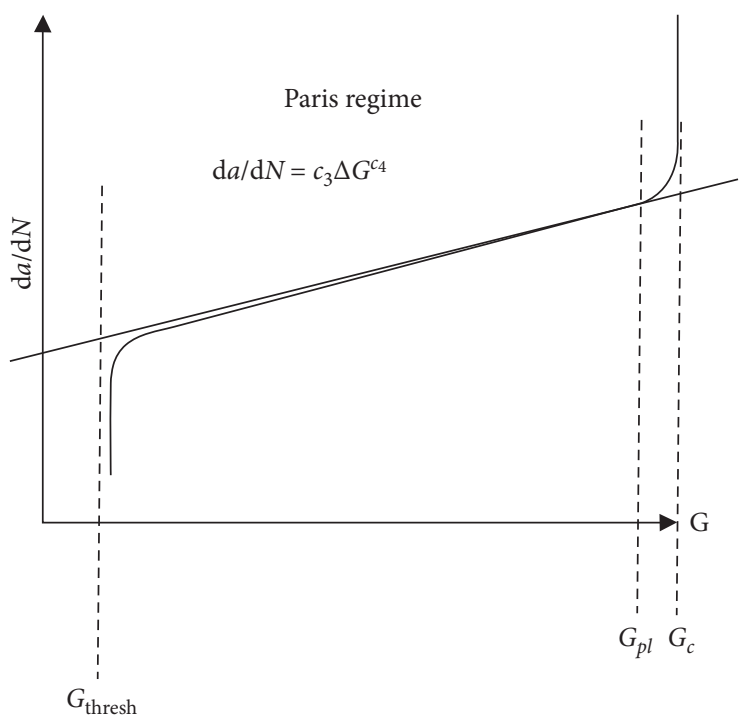

Figure 4: Fatigue crack growth rate-Paris regime (central region).

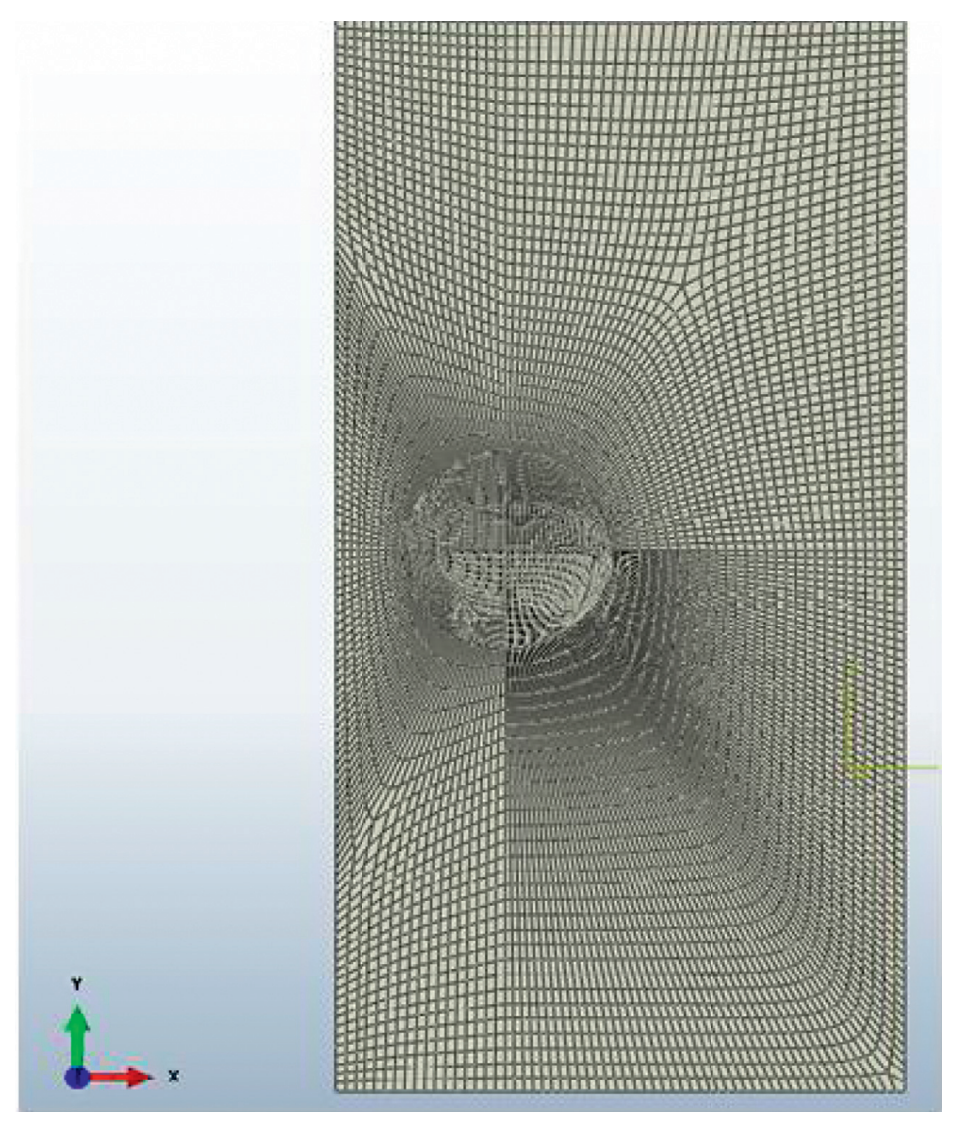

(a)

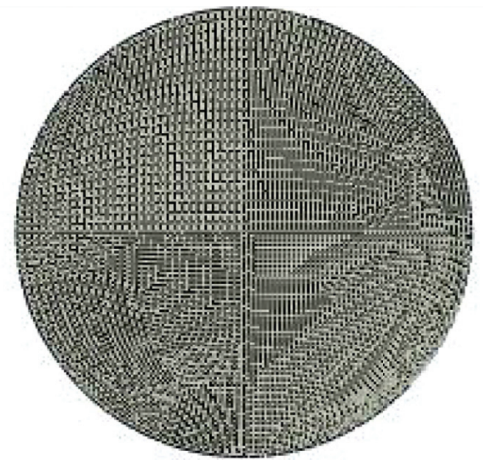

(b)

Figure 5: (a) Global mesh and (b) local mesh. 


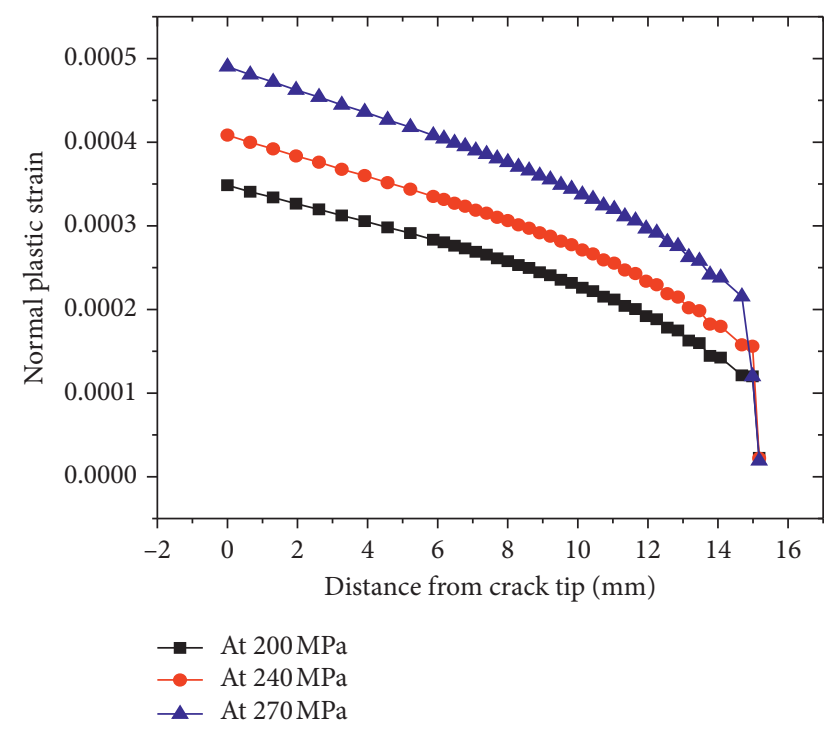

Figure 6: Normal strain vs. distance from crack tip at different loads.

release rate, $\Delta G$. In each cycle, the crack growth rate is defined by the Paris law:

$$
\left(\frac{\mathrm{d} a}{\mathrm{~d} N_{m}}\right)=c_{3} \Delta G^{C_{4}},
$$

where $c_{3}$ and $C_{4}$ are material constants and subscript, $m$, represents the mechanical fatigue. The values of $c_{3}$ and $c_{4}$ are calculated by $c_{3}=c E^{m / 2}$ and $c_{4}=m / 2$, where the typical values of " $m$ ", for steel, are in the range of 3-5 and that of " $c$ " is in the range of $10^{-8}$ to $10^{-12} \mathrm{~mm} /$ cycle $\cdot \mathrm{MPa}^{1 / 2}$.

\subsection{Finite Element Model and Crack Growth Simulation.} A typical 4-node finite element mesh model with 12093 elements is shown in Figure 5(a) where $X$-coordinate is parallel to the direction of crack and $Y$-coordinate is normal to the direction of crack. A small subset in circular form is generated around the crack tip to visualize the crack growth rate clearly (see Figure 5(b))

Crack simulation consists of three steps: crack initiation, crack propagation, and failure [38]. All these steps are simulated in the ABAQUS 6.14 software without any remeshing near the crack tip. The maximum principal stress criterion is used which is represented as follows:

$$
f=\left\{\frac{\sigma_{\max }}{\sigma_{\max }^{0}}\right\},
$$

where $\sigma_{\max }^{0}$ represents the maximum allowable principal stress and the damage starts when the ratio becomes unity [39]. The damage evolution technique based on power law has been used to simulate crack propagation. In the case of static loading, the step time is $1 \mathrm{sec}$ with 0.001 increment size, and in the case of direct cyclic loading (low-cyclic fatigue), the step time is the same for $10^{4}$ cycles with 0.01 increment size. The total time for the simulations is more than $24 \mathrm{hrs}$.
TABLE 3: Hydrochemical properties of SS-304 [40].

\begin{tabular}{lc}
\hline Parameter & Values \\
\hline Atomic weight, $M$ (g/mole) & 55.6 \\
Number of equivalents exchanged, $Z$ & 2.67 \\
Oxidation current density, $i_{0}\left(A / \mathrm{mm}^{2}\right)$ & 0.00015 \\
Exponent of current decay, $m$ & 0.4 \\
Fracture strain of oxide film, $\epsilon_{\mathrm{f}}$ & 0.0025 \\
Faraday's constant & 96500 \\
\hline
\end{tabular}

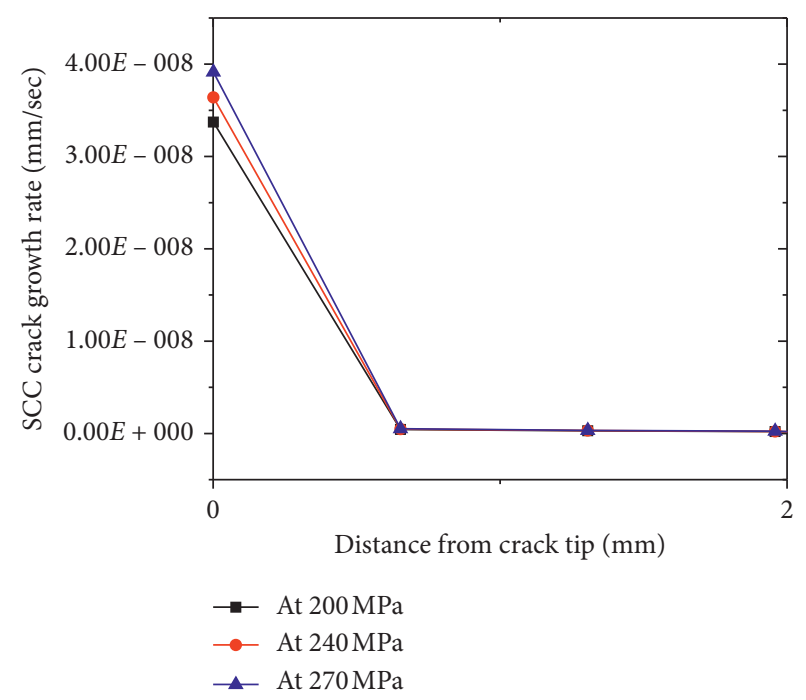

FIgURE 7: SCC crack growth rate vs. distance from crack tip.

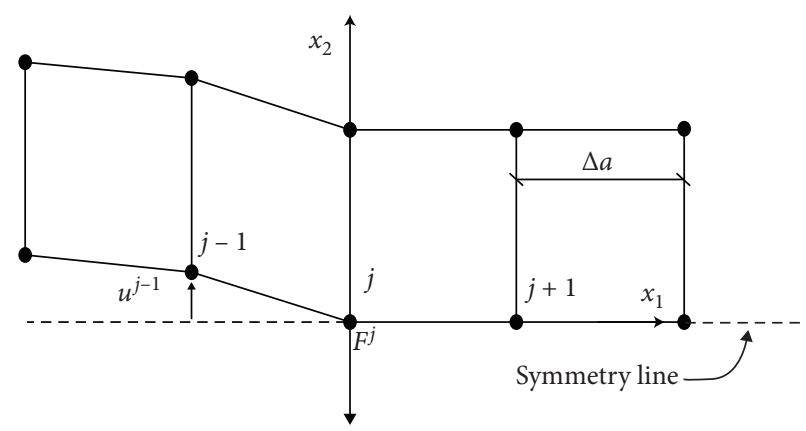

FIgURE 8: Schematic of MCCI technique for 4 nodes.

\section{Results and Discussions}

4.1. Normal Plastic Strain. In order to calculate SCC crack growth rate $(\mathrm{mm} / \mathrm{cycle}), \mathrm{d} a / \mathrm{d} N_{\mathrm{Scc}}$, firstly SCC crack growth rate in $\mathrm{mm} / \mathrm{sec}$ is calculated. From equation (10), it is obvious that in order to calculate the $\mathrm{d} a / \mathrm{d} t(\mathrm{~mm} / \mathrm{sec})$, strain gradient, $\mathrm{d} \varepsilon_{p} / \mathrm{d} r$, is required. The strain vs. distance from the crack tip at three of the applied loads is shown in Figure 6. These values have been extracted from ABAQUS directly, and the strain gradient $\mathrm{d} \varepsilon_{p} / \mathrm{d} r$ is measured according to the process defined in Section 3.2 (see Figure 3). 


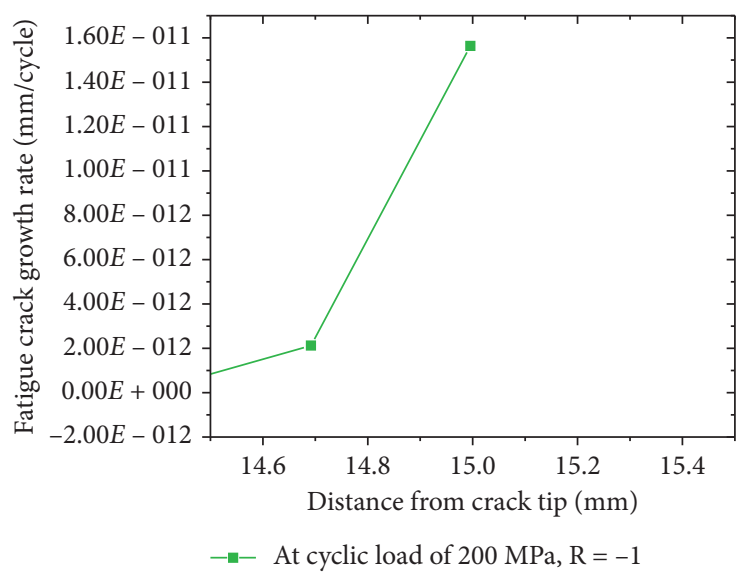

Figure 9: Fatigue crack growth rate vs. distance from crack tip.

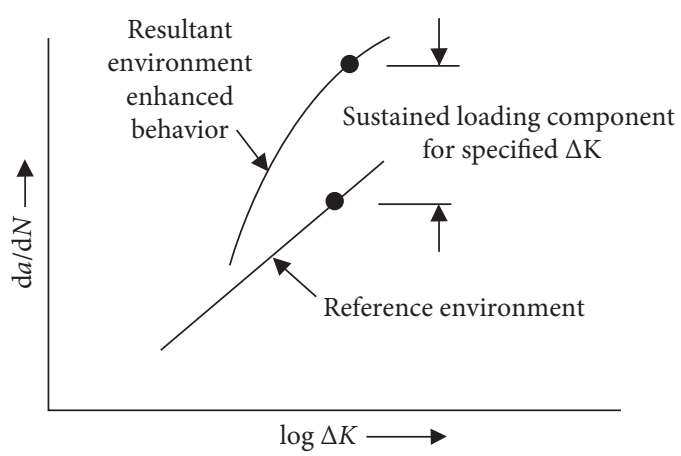

(a)

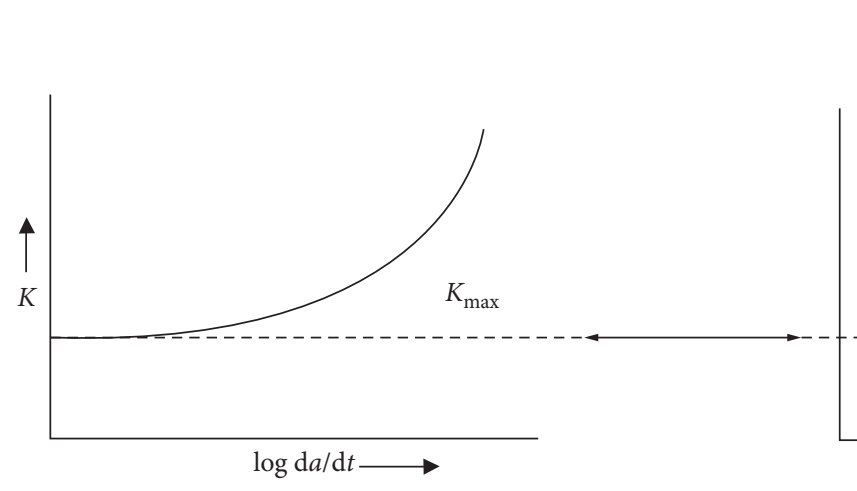

(b)

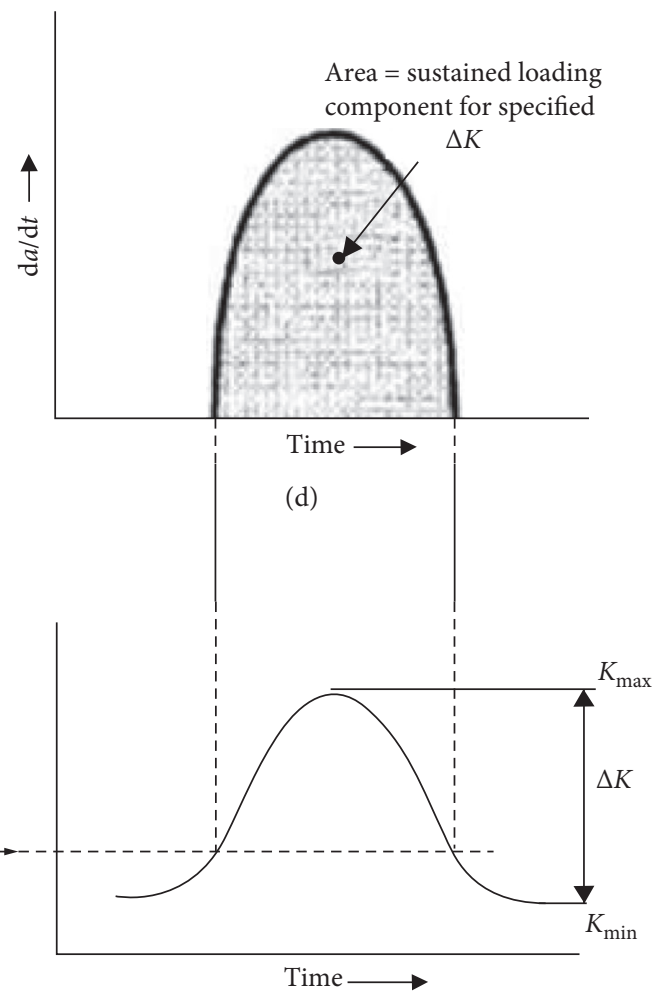

(c)

FIGURE 10: Schematic diagram illustrating the linear superposition hypothesis: (a) integrating effect on the environment of fatigue crack growth rate; (b) crack growth rate under sustained load in aggressive environment; (c) environmental contribution; (d) sustained loading component due to constant loading.

4.2. SCC Crack Growth Rate, da/dt. The SCC crack growth rate $(\mathrm{mm} / \mathrm{sec})$ is measured using equation (10). The hydrochemical properties of SS-304 at an elevated temperature are shown in Table 3. The values of $\kappa_{a}^{\prime}$ is taken to be $8.4 \times 10^{-7}$. The SCC crack growth rate is shown in Figure 7 .

The SCC crack growth rate varies with the strain gradient values and becomes stable as the values of the strain gradient become low.
4.3. LCF Crack Growth Rate, $d a / d N_{m}$. The LCF crack growth rate is measured by using equation (12), for which the values of energy release rate, $\Delta G$, are required. For the elasticplastic model, the values of strain energy cannot be calculated directly from ABAQUS. In order to calculate the values of strain energy, modified crack closure integral (MCCI) technique for 4-node is used in this research. MCCI is a method of calculating energy release rate, $\Delta G$, using nodal 


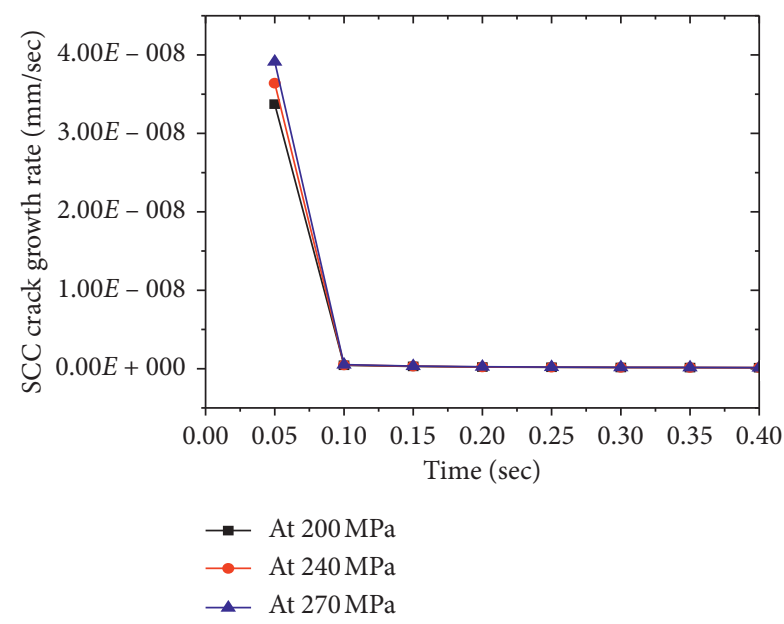

FIGURE 11: SCC crack growth rate $(\mathrm{mm} / \mathrm{sec})$ vs. time.

displacement $u_{i}^{j}$ and the nodal forces $F^{j+1}$ where $j$ represents the nodal index and $i$ represents the direction corresponding to the Cartesian coordinate [41, 42]. The 4-node square linear element (see Figure 8), has distance $\Delta a$ between $j$ and $j+1$ nodes. If the crack propagates between $j$ and $j+1$, then the crack opening displacement, $u^{j}$, will be the displacement at $j$ node and the force $F^{j+1}$ will be the force at new node $j+1$. And the energy release rate at $j+1$ node is given by

$$
\Delta G=\frac{1}{2 \Delta a} u^{j} F^{j+1}
$$

Using the values of $\Delta G, c_{3}$, and $C_{4}$ in equation (12), the fatigue crack growth rate is measured (see Figure 9).

4.4. Joint or Interactive Effect on Crack Growth Rate. There are some approaches that incorporate SCC/environmental effects in the fatigue crack propagation rate and vice versa in the literature [43]. The simplest and empirical approach is the linear superposition method for the crack growth rate. It was first given by Wei, Landes, Gallagher, and Bucci [44]. According to superposition method, the environment enhanced equivalent/overall crack growth rate (sum of SCC and fatigue crack growth rate), $\left[\mathrm{d} a / \mathrm{d} N_{o}\right]_{m}$, is given by combining the inert fatigue crack growth rate, $\mathrm{d} a / \mathrm{d} N_{m}$, and time-dependent, monotonic load environment crack growth rate, $\mathrm{d} a / \mathrm{d} N_{S c c}$, that is,

$$
\left[\frac{\mathrm{d} a}{\mathrm{~d} N_{o}}\right]_{m}=\frac{\mathrm{d} a}{\mathrm{~d} N_{m}}+\frac{\mathrm{d} a}{\mathrm{~d} N_{\mathrm{Scc}}},
$$

where $\mathrm{d} a / \mathrm{d} N_{m}$ and $\mathrm{d} a / \mathrm{dN}_{\mathrm{Scc}}$ are in $\mathrm{mm} /$ cycle.d $a / \mathrm{d} N_{m}$ computed in Section 4.3 is already in $\mathrm{mm} / \mathrm{sec}$, while $\mathrm{d} a / \mathrm{d} t$ ( $\mathrm{mm} / \mathrm{sec})$ computed in Section 4.2 is converted into $\mathrm{mm} /$ cycle, $\mathrm{d} a / \mathrm{d} N_{\mathrm{Scc}}$, which is computed by integrating the sustained crack growth data and applied time-dependent stress intensity factor in a single fatigue load cycle $k_{(t)}$, that is,

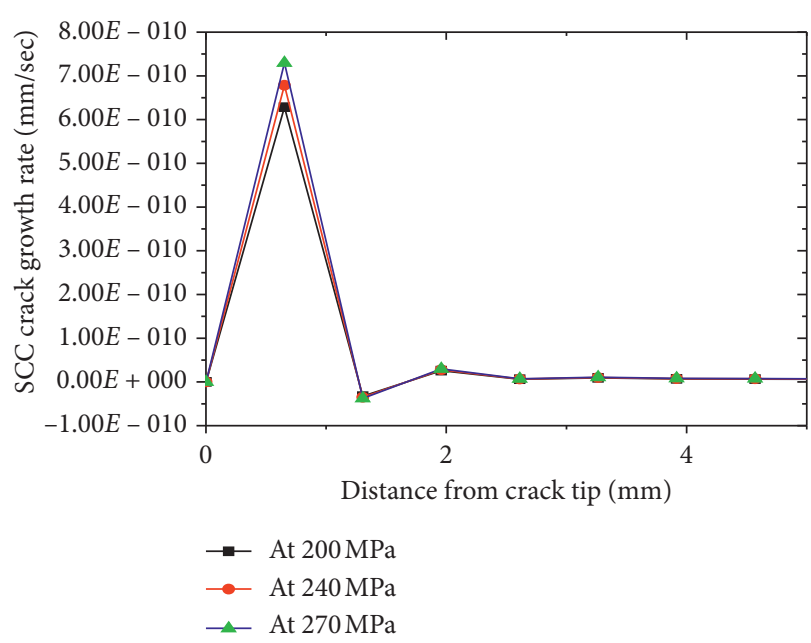

FIGURE 12: SCC crack growth rate ( $\mathrm{mm} /$ cycle) vs. distance from crack tip.

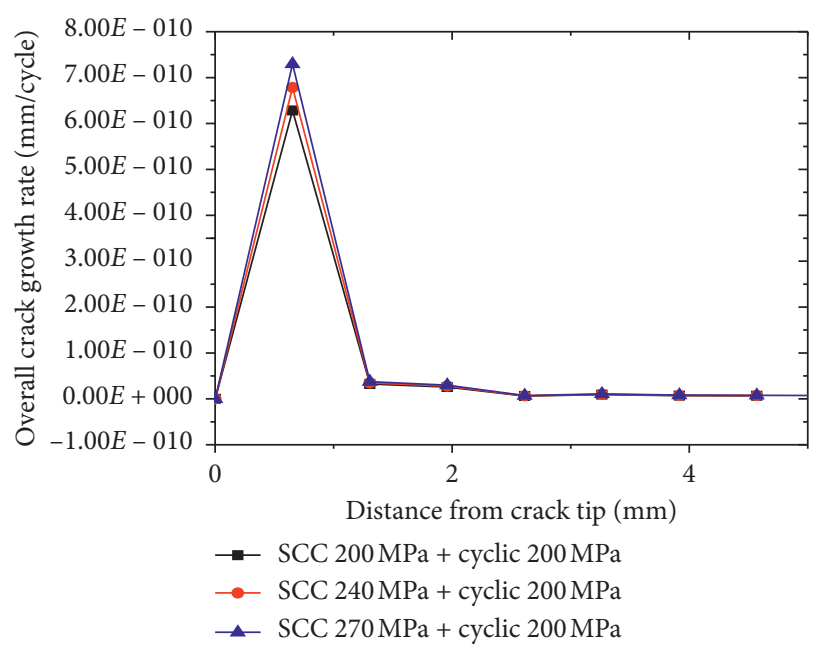

FIGURE 13: Overall crack growth rate vs. distance from crack tip.

$$
\frac{\mathrm{d} a}{\mathrm{~d} N_{\mathrm{Scc}}}=\int_{0}^{1 / f}\left[\frac{\mathrm{d} a}{\mathrm{~d} t_{(k)}}\right]\left[k_{(t)}\right] \mathrm{d}_{t} .
$$

In order to convert $\mathrm{d} a / \mathrm{d} t$ into $\mathrm{d} a / \mathrm{d} N_{\mathrm{Scc}}$, plot between $\mathrm{d} a / \mathrm{d} t$ and the time involved is needed which can be integrated over time as shown in Figure 11. Figure 12 shows the SCC crack growth rate in $\mathrm{mm} /$ cycle.

Figure 13 represents the joint (overall) effect due to fatigue (cyclic) and SCC load on the crack. It is obvious from Figures 12 and 13 that major contribution to the overall crack growth rate is due to SCC.

\section{Conclusions}

A new approach to interact fatigue and SCC mechanism has been introduced in this research. The overall crack growth rate calculated in Figure 13 is different from that in the case 
of SCC (see Figure 12) and LCF (see Figure 9) crack growth rate separately. The difference between SCC crack growth rate and overall crack growth is not as large as that in the case of LFC and overall crack growth rate; this is the reason that the SCC is the main cause of failure in the structures. Three sets of SCC loads have been taken and comparison is done. As the load in SCC is increasing, the difference in the overall crack growth rate $\left[\left(\mathrm{d} a / \mathrm{d} N_{o}\right)\right]_{m}$ and $\mathrm{d} a / \mathrm{d} N_{\mathrm{Scc}}$ is decreasing.

An approach to convert $\mathrm{d} a / \mathrm{d} t(\mathrm{~mm} / \mathrm{sec})$ into $\mathrm{d} a / \mathrm{d} N_{\mathrm{Scc}}$ ( $\mathrm{mm} /$ cycle) has been studied and implemented in this research. It is obvious from Figures 10(d) and 12 that the results have the same pattern as described in theory.

The idea to calculate the fatigue crack growth rate has been used in Section 4.3, and the results are closer to the theoretical results.

The SCC and fatigue both are present at a time on the same crack, and the effect of the fatigue on the SCC or the effect of the SCC on the fatigue cannot be neglected in the analysis.

\section{Data Availability}

The data (from experimental work) used to support the findings of this study are available in supplementary files.

\section{Conflicts of Interest}

The authors declare that there are no conflicts of interest regarding the publication of this paper.

\section{Acknowledgments}

This work was financially supported by the International Exchange Programme Scheme, a project by National Natural Science Foundation of China and Royal Society (51811530311), National Science Foundation of China (51475362), and National Science Foundation of Shaanxi Province (2018JQ5193).

\section{Supplementary Materials}

The supplementary materials submitted along with the manuscript are the experimental data of the true tensile stress-strain curve of stainless steel-304 at an elevated temperature of $320^{\circ}$ Celsius (for figure 2(a)). In the lightwater reactors, the temperature is normally too high. The experiment for these data, for more than 24 hours, has been conducted on the "Slow Strain Rate Stress Corrosion Testing Machine" available in the Fracture Mechanics lab of Xi'an University of Science and Technology, Xi'an, China. From experimental data, the nominal/engineering stress-strain values were obtained which were converted into true stressstrain values using conversions to use in simulations. The diagram of the machine and the updated data file containing engineering and true stress-strain values along with the conversions are also attached herewith. (Supplementary Materials)

\section{References}

[1] D. Buckthorpe, V. Filatov, and A Tashkinov, "Review of provisions on corrosion fatigue and stress corrosion in WWER and western LWR codes and standards," in Proceedings of the Transactions of the 17th international Conference on structural Mechanics in Reactor Tefchnology (SMiRT 17), pp. 1-8, Prague, Czech republic, August 2003.

[2] ASM Handbook Committee, Failure Analysis and Prevention Handbook, ASM International, Cleveland, OH, USA, 2002.

[3] L. P. Pook, Fatigue of Materials-S. Suresh, Elsevier, Amsterdam, Netherlands, 1992.

[4] W. Soboyejo, Fatigue of Materials, Cambridge University Press, Cambridge, UK, 2nd edition, 2002.

[5] V. Doquet, G. Hénaff, T. Palin-Luc, and M. Risbet, "Fatigue crack initiation and propagation," Mechanics-Microstructure-Corrosion Coupling, Elsevier, Amsterdam, Netherlands, pp. 65-90, 2019.

[6] Q. Xin, "Durability and reliability in diesel engine system design," Diesel Engine System Design, pp. 113-202, Elsevier, Amsterdam, Netherlands, 2013.

[7] R. Branco, J. Costa, F. Berto et al., "Low-cycle fatigue behaviour of AISI $18 \mathrm{Ni} 300$ maraging steel produced by selective laser melting," Metals, vol. 8, no. 1, 2018.

[8] A. Pineau, "Low-cycle fatigue," in Fatigue of Materials and Structures: Fundamentals, Wiley, London, UK, 2013.

[9] C. A. Loto, "Stress corrosion cracking: characteristics, mechanisms and experimental study," The International Journal of Advanced Manufacturing Technology, vol. 93, no. 9-12, 2017.

[10] A. A. Sheinker and J. D. Wood, Stress Corrosion Cracking of a High Strength Steel, ASTM Special Technical Publication, West Conshohocken, PA, USA, 1972.

[11] R. N. Parkins, Environment Sensitive Fracture of Metallic Materials, Elsevier, Amsterdam, Netherlands, 1989.

[12] L. Zhao, X. He, J. Kang, and T. Wei, "Analysis of interface fracture on piping welded joint with continuous material properties," in Proceedings of the 2013 4th International Conference On Digital Manufacturing And Automation, (ICDMA 2013), Qingdao, China, June 2013.

[13] X. He and T. Shoji, "Quantitative prediction of EAC crack growth rate of sensitized type 304 stainless steel in boiling water reactor environments based on EPFEM," Journal of Pressure Vessel Technology, vol. 129, no. 3, 2007.

[14] B. N. Leis and T. W. Crooker, Corrosion Fatigue: Mechanics, Metallurgy, Electrochemistry, and Engineering, a Symposium, ASTM Special Technical Publication, West Conshohocken, PA, USA, 1983.

[15] J. Predan, R. Pippan, and N. Gubeljak, "Fatigue crack propagation in threshold regime under residual stresses," International Journal of Fatigue, vol. 32, no. 7, pp. 1050-1058, 2010.

[16] P. Paris and F. Erdogan, "A critical analysis of crack propagation laws," Journal of Fluids Engineering, vol. 85, no. 4, pp. 528-533, 1963.

[17] W. Elber, "Fatigue crack closure under cyclic tension," Engineering Fracture Mechanics, vol. 2, no. 1, pp. 37-45, 1970.

[18] D. Kujawski, "Utilization of partial crack closure for fatigue crack growth modeling," Engineering Fracture Mechanics, vol. 69, no. 12, pp. 1315-1324, 2002.

[19] S. Dinda and D. Kujawski, "Correlation and prediction of fatigue crack growth for different $R$-ratios using $K_{\max }$ and 
$\Delta K+$ parameters," Engineering Fracture Mechanics, vol. 71, no. 12, pp. 1779-1790, 2004.

[20] L. Zhu and M.-P. Jia, "A new approach for the influence of residual stress on fatigue crack propagation," Results in Physics, vol. 7, pp. 2204-2212, 2017.

[21] B. Kerezsi, J. W. H. Price, and R. Ibrahim, "A two-stage model for predicting crack growth due to repeated thermal shock," Engineering Fracture Mechanics, vol. 70, no. 6, pp. 721-730, 2003.

[22] G. Murtaza and R. Akid, "Empirical corrosion fatigue life prediction models of a high strength steel," Engineering Fracture Mechanics, vol. 67, no. 5, pp. 461-474, 2000.

[23] H. Xue, Z. Li, Z. Lu, and T. Shoji, "The effect of a single tensile overload on stress corrosion cracking growth of stainless steel in a light water reactor environment," Nuclear Engineering and Design, vol. 241, no. 3, pp. 731-738, 2011.

[24] P. T. Gilbert, "Corrosion-fatigue," International Materials Reviews, vol. 1, no. 1, pp. 379-417, 1956.

[25] J. R. Donahue, A. B. Lass, and J. T. Burns, "The interaction of corrosion fatigue and stress-corrosion cracking in a precipitation-hardened martensitic stainless steel," NPJ Materials Degradation, vol. 1, no. 1, 2017.

[26] W. Chen, P. Spätig, and H. P. Seifert, "Fatigue behavior of 316L austenitic steel in air and LWR environment with and without mean stress," in Proceedings of the 14th International Conference on Fracture (ICF 2017), Rhodes, Greece, May 2017.

[27] H. E. Hänninen, "6.01-stress corrosion cracking," Comprehensive Structural Integrity, vol. 6, pp. 1-29, Elsevier, Amsterdam, Netherlands, 2007.

[28] M. Dahlberg and D. Bremberg, "Fatigue margins for austenitic stainless steels in ASME boiler and pressure vessel code-a literature study," Technical report, Stral Sakerhets Myndigheten Swedish Radiation Safety Authority, Stockholm, Sweden, 2012.

[29] X. Hu, K. A. Terrani, B. D. Wirth, and L. L. Snead, "Hydrogen permeation in $\mathrm{FeCrAl}$ alloys for LWR cladding application," Journal of Nuclear Materials, vol. 461, pp. 282-291, 2015.

[30] S. Szklarska-Smialowska and G. Cragnolino, "Stress corrosion cracking of sensitized type 304 stainless steel in oxygenated pure water at elevated temperatures (review)," Corrosion, vol. 36, no. 12, pp. 653-665, 1980.

[31] J. Fish and T. Belytschko, "Commercial finite element program ABAQUS tutorials," in A First Course in Finite Elements, Wiley, Hoboken, NJ, USA, 2007.

[32] C. Zhang, P. Cao, Y. Cao, and J. Li, "Using finite element software to simulation fracture behavior of three-point bending beam with initial crack," Journal of Software, vol. 8, no. 5, pp. 1145-1150, 2013.

[33] A. Sutradhar and G. H. Paulino, "Symmetric Galerkin boundary element computation of T-stress and stress intensity factors for mixed-mode cracks by the interaction integral method," Engineering Analysis with Boundary Elements, vol. 28, no. 11, pp. 1335-1350, 2004.

[34] T. Belytschko and T. Black, "Elastic crack growth in finite elements with minimal remeshing," International Journal for Numerical Methods in Engineering, vol. 45, no. 5, pp. 601-620, 1999.

[35] F. P. Ford, "3 Mechanisms of environmentally-assisted cracking," International Journal of Pressure Vessels and Piping, vol. 40, no. 5, pp. 343-362, 1989.

[36] T. Shoji, Z. Lu, and H. Murakami, "Formulating stress corrosion cracking growth rates by combination of crack tip mechanics and crack tip oxidation kinetics," Corrosion Science, vol. 52, no. 3, pp. 769-779, 2010.
[37] H. Xue, Y. Sato, and T. Shoji, "Quantitative estimation of the growth of environmentally assisted cracks at flaws in light water reactor components," Journal of Pressure Vessel Technology, vol. 131, no. 1, 2009.

[38] E. Giner, N. Sukumar, J. E. Tarancón, and F. J. Fuenmayor, "An abaqus implementation of the extended finite element method," Engineering Fracture Mechanics, vol. 76, no. 3, pp. 347-368, 2009.

[39] Dassault Systèmes, Manual Abaqus 6.14, Dassault Systèmes, Vélizy-Villacoublay, France, 2014.

[40] F. Q. Yang, H. Xue, L. Y. Zhao, and X. R. Fang, “A quantitative prediction model of SCC rate for nuclear structure materials in high temperature water based on crack tip creep strain rate," Nuclear Engineering and Design, vol. 278, pp. 686-692, 2014.

[41] E. F. Rybicki and M. F. Kanninen, "A finite element calculation of stress intensity factors by a modified crack closure integral," Engineering Fracture Mechanics, vol. 9, no. 4, pp. 931-938, 1977.

[42] R. Sethuraman and S. K. Maiti, "Finite element based computation of strain energy release rate by modified crack closure integral," Engineering Fracture Mechanics, vol. 30, no. 2, pp. 227-231, 1988.

[43] J. Lankford and S. Hudakjr, "Relevance of the small crack problem to lifetime prediction in gas turbines," International Journal of Fatigue, vol. 9, no. 2, pp. 87-93, 1987.

[44] S. S. Kim, S. J. Choe, and K. S. Shin, "Quantitative models on corrosion fatigue crack growth rates in metals: part I. Overview of quantitative crack growth models," Metals and Materials, vol. 4, no. 1, pp. 1-13, 1998. 